\title{
Creating a Pathway to Leadership for Women in Gastroenterology
}

\author{
Laura C. Rotundo · Jill K. J. Gaidos ${ }^{2}$ \\ Accepted: 21 September 2021 / Published online: 8 October 2021 \\ (C) The Author(s), under exclusive licence to Springer Science+Business Media, LLC, part of Springer Nature 2021
}

Gastroenterology has long been a male-dominated field. As of 2019, of the 15,000 active gastroenterologists in the USA, only $18.9 \%$ are women [1]. Despite an equal number of women entering medicine, the percentage of women physicians entering GI fellowship (30\%) remains disproportionately lower than in other medicine subspecialties [2]. Moreover, women are underrepresented at all levels of leadership in academic medicine. As of 2018, women comprised only $37 \%$ of full-time associate professors and $25 \%$ of full professors [3]. At higher levels of leadership, the gender inequality is even greater: Only $29 \%$ of division or section chief positions, $18.9 \%$ of department chairs, and $18 \%$ of medical school dean positions are held by women [3]. As these academic leadership positions are typically only offered to associate and full professors, the likelihood of promotion in academic medicine is lower and takes longer for women compared with men, which has not significantly changed over the past 35 years[4]. While leadership gender inequality is likely multifactorial [5], the barriers that prevent women from promotion and leadership opportunities can be overcome.

\section{Barriers to Women in Leadership Positions}

Gender inequality in leadership in gastroenterology is multifaceted. Some attribute this gap to the "status quo bias": When departments or sections are doing well, there is no impetus for change. Since men more commonly hold and therefore maintain these leadership positions, there are fewer

Jill K. J. Gaidos

jill.gaidos@yale.edu

1 Section of Digestive Diseases, Department of Medicine, Yale School of Medicine, Yale University, New Haven, CT 06510, USA

2 Vice Chief Clinical Research, Section of Digestive Diseases, Director of Clinical Research, Yale Inflammatory Bowel Disease Program, 40 Temple Street, Suite 1A, New Haven, CT 06510, USA opportunities for women to advance in the field. Another cited reason for the gender gap in leadership is due to a lack of role models. As women are underrepresented in medicine, there are fewer opportunities for trainees and junior faculty to identify and emulate leaders of the same gender. Encouragingly, the visibility of women in leadership positions has improved over the past several years, particularly in 2017 when for the first time all four major GI societies were led by women presidents [6].

Another major deficiency that impacts advancement for women in gastroenterology is a lack of mentorship. Among academic gastroenterologists, more women than men reported having difficulty finding a mentor $(44.4 \%$ vs $16.0 \%, P<0.0001$ ) [7]. One cited reason was that they were unable to find a mentor of the same gender $(12.8 \%$ vs $0.9 \%, \mathrm{P}=0.0004)$, which impacts promotion rates, career satisfaction, burnout rates, and attrition [7]. Women also are less likely to have sponsorship, which creates opportunities for promotion and is equally if not more important than mentorship.

Another theory is that there are fewer qualified women candidates to fill leadership positions. The pipeline for women entering gastroenterology has remained stable for the past several years [1]. The current area of need is repairing the "leaky pipe," i.e., preventing women from leaving gastroenterology. Around $40 \%$ of women will reduce their commitment to part-time or leave medicine altogether within 6 years of completing their training due to competing demands between work and home life [8]. For women who do not leave early in their career, they may face additional challenges with early promotion, sometimes referred to as the "broken rung." Other challenges include bias, unequal wages, pregnancy- and motherhood-related discrimination, and sexual harassment [9]. Further, due to the disproportionate burden of household chores falling on women, there is less time to complete research or prepare presentations outside of work hours. Furthermore, for employment in general, women apply for positions for which they are $100 \%$ qualified, whereas men apply when they meet only $60 \%$ of the qualifications [10]. As formal leadership training is not a 
routine part of medical programs, it falls on women to seek their own training.

\section{Ways to Overcome Gender Inequity in GI Leadership}

Overcoming these barriers will require changes in multiple areas. For employers, whether in academic centers or private practices, the keys are to make changes that will not only aid with the promotion of women but also help to keep women in medicine. The COVID pandemic has placed greater stress on women [11, 12] with the resultant exodus furthering the gap in inequity. Recommendations from the American Medical Women's Association \#GiveHerAReasonToStay in healthcare movement include fair pay, objective promotion criteria, a work environment free from harassment, mentorship and sponsorship for specific academic tracks, and flexible work schedules and childcare [13]. It is also essential to reevaluate the promotion criteria for bias since the traditional requirements, such as having grant-funded research and publications, tend to be lower for women [14]. Nevertheless, women and minorities are more often asked to be mentors and to participate on committees, roles which are not routinely recognized as equally important in the promotion criteria.

There are ways for women gastroenterologists to carve a leadership path (Table 1). Leadership opportunities can come from one's institution or current practice, from local branches of national organizations, and from national GI societies. Having an idea of your leadership goals will help guide your path. The most important first step is to get involved in an area of interest, such as joining a national GI society committee. Being on a committee provides an opportunity to network with other GI doctors outside of your institution or current practice, which can lead to even more opportunities [15], as well as allowing you to gain leadership experience and establish a national reputation. I (JG) joined the American College of Gastroenterology (ACG) Women in GI Committee as a gastroenterology fellow. I organized events and moderated trainee sessions at the ACG National meeting, building up my leadership experience, adding to my $\mathrm{CV}$ for promotion, but also expanding my network as I invited faculty who I wanted to meet.

Saying "yes" to opportunities is the best way to learn and grow. Realize that you do not need to meet $100 \%$ of the qualifications to apply for a position; you can and will gain additional skills once you are in the position. Also recognize that if others did not think you were qualified, you would not have been offered the opportunity. My active participation and contributions to the ACG Women in GI Committee led to my nomination to be committee Chair. My first reaction was that I was not fully prepared; however, I chose to say yes and challenge myself. Realize that as a woman, you are likely to have well-developed social and networking skills that are essential to gaining leadership positions and advancing in your field. Finally, sharing your goals with others will create an opportunity to discuss your experience, identify any gaps you can address to meet these goals, and inform others so they can nominate you when a position becomes available.

Table 1 Ways to Build Your Leadership Experience

\begin{tabular}{|c|c|}
\hline Opportunity & Examples \\
\hline Get Involved & $\begin{array}{l}\text { Join a committee at your institution, local organization or national GI society in an area that interests you so } \\
\text { that it will overlap with your career goals }\end{array}$ \\
\hline Gain Leadership Experience & $\begin{array}{l}\text { Include completed committee work in your CV to show your leadership experience, which is key when being } \\
\text { considered for leadership opportunities. For example, include in your CV your role as task force leader for a } \\
\text { project on a national society committee and the outcome of that project }\end{array}$ \\
\hline Build Your National Reputation & $\begin{array}{l}\text { Include completed committee work in your } \mathrm{CV} \text { to establish your national reputation, which is key for academic } \\
\text { promotion. For example, organizing, moderating, and/or participating in a panel discussion at a national } \\
\text { meeting or reviewing and updating patient education materials for a national GI society }\end{array}$ \\
\hline Grow Your Network & $\begin{array}{l}\text { Networking is about meeting new people and establishing relationships. When you build your network, you are } \\
\text { increasing your chances for more opportunities to come your way while also increasing the number of people } \\
\text { you could sponsor for future opportunities }\end{array}$ \\
\hline Say Yes & $\begin{array}{l}\text { When offered an opportunity that will help you to achieve your 5- to 10-year career goals, take it. You do not } \\
\text { need to be } 100 \% \text { qualified; you are expected to learn while you are already in the position. While learning } \\
\text { to say no is an excellent skill for time management and for eliminating extraneous duties that do not help } \\
\text { you achieve your career goals, make sure you also learn when to say yes. One way to determine whether you } \\
\text { should say yes is to give yourself time to think about the opportunity and reassess your goals }\end{array}$ \\
\hline Share Your Goals & $\begin{array}{l}\text { If others are not aware of your career goals, they will be less likely to nominate you when a position becomes } \\
\text { available }\end{array}$ \\
\hline
\end{tabular}




\section{Conclusion}

The cause of our current gender gap among leaders in gastroenterology is multifactorial but is not insurmountable. Changes are needed to eliminate bias in the promotion pathways that recognize academic duties and service; these changes are key to success as these activities are more commonly performed by women, including mentoring and committee work. Providing equal pay for equal work and ensuring that everyone has a safe work environment are basic requests that have not yet been universally fulfilled. There are strategies and opportunities for women to create their own pathway toward leadership. For women who feel alone in their current practice setting or need help taking the first steps on their leadership path, there are women's committees and mentoring programs within each of the national GI societies where you can reach out for guidance and support. Overall, it falls upon our generation to continue making progress despite these hardships as the next generation of women gastroenterologists join our ranks.

\section{Declarations}

Conflict of interest The authors have no conflicts of interest to disclose.

\section{References}

1. Colleges AoAM. Physician specialty data report. Association of American Medical Colleges Washington, DC; 2020.

2. Pallardy C. Male \& female active physicians: 70 statistics by specialty. Becker's GI \& Endoscopy, 2015.

3. Colleges AoAM. 2018-2019 The state of women in academic medicine: exploring pathways to equity. 2019.
4. Richter KP, Clark L, Wick JA et al. Women physicians and promotion in academic medicine. N Engl J Med 2020;383:2148-2157.

5. National Academies of Sciences E, Medicine. Promising practices for addressing the underrepresentation of women in science, engineering, and medicine: Opening doors. National Academies Press; 2020.

6. Lok A, Burke CA, Crowe SE, Woods KL. Society leadership and diversity: hail to the women! Gastrointestinal endoscopy 2017;86:413-415.

7. Rabinowitz LG, Grinspan LT, Zylberberg HM, et al. Survey Finds Gender Disparities Impact Both Women Mentors and Mentees in Gastroenterology. Am J Gastroenterol 2021:10.14309.

8. Frank E, Zhao Z, Sen S, Guille C. Gender disparities in work and parental status among early career physicians. JAMA network open. 2019;2:e198340-e198340.

9. Lewiss RE, Silver JK, Bernstein CA, Mills AM, Overholser B, Spector ND. Is academic medicine making mid-career women physicians invisible? J Women's Health. 2020;29:187-192.

10. Mohr TS. Why women don't apply for jobs unless they're $100 \%$ qualified. Harvard Business Review. 2014;25.

11. Myers KR, Tham WY, Yin Y et al. Unequal effects of the COVID19 pandemic on scientists. Nat Hum Behav 2020;4:880-883.

12. Andersen JP, Nielsen MW, Simone NL, Lewiss RE, Jagsi R. Meta-Research: COVID-19 medical papers have fewer women first authors than expected. elife. 2020;9:e58807.

13. Give Her A Reason to Stay In Healthcare. 2021; available at https://www.amwa-doc.org/our-work/initiatives/gender-equitytask-force/give-her-a-reason-to-stay-in-healthcare/

14. Oliveira DF, Ma Y, Woodruff TK, Uzzi B. Comparison of National Institutes of Health grant amounts to first-time male and female principal investigators. JAMA 2019;321:898-900.

15. Gaidos JK, Hass DJ, Kane SV. How to Strategically Build Your Network for Early Career Gastroenterologists. Gastroenterology 2021;160:1461-1466.

Publisher's Note Springer Nature remains neutral with regard to jurisdictional claims in published maps and institutional affiliations. 